As accepted for publication, http://journals.humankinetics.com/ijsnem

1 Beneficial physiological effects with blackcurrant intake in endurance athletes

2

3 Authors:

Mark Elisabeth Theodorus Willems, Stephen David Myers, Mandy

4

Lucinda Gault, Matthew David Cook

5

6

Affliliation:

University of Chichester

7

Department of Sport \& Exercise Sciences

8

College Lane

9

Chichester, PO19 6PE

10

United Kingdom

11

12 Running head:

Blackcurrant and exercise-mediated effects

13

14 Corresponding author: $\quad$ Professor Mark Willems

Phone: +44 (0)1243 816468

16

Email: $\underline{\text { m.willems@ @hi.ac.uk }}$

\title{
19 ABSTRACT
}

20 Blackcurrant contains anthocyanins, known to influence vasorelaxation and peripheral blood

21 flow. We examined the effects of 7 days intake of Sujon New Zealand blackcurrant powder

22 (6g/day) on the lactate curve, maximum oxygen uptake, and cardiovascular responses at rest and

23 during cycling. Thirteen trained triathletes with $>3$ yrs experience ( 8 men, age: $38 \pm 8$ yrs, body

As accepted for publication, http://journals.humankinetics.com/ijsnem 
As accepted for publication, http://journals.humankinetics.com/ijsnem

24 mass: $71 \pm 9 \mathrm{~kg}, \mathrm{BF} \%$ : 19 $\pm 5 \%$, mean $\pm \mathrm{SD}$ ) performed two incremental cycling protocols with

25 recording of physiological and cardiovascular responses (Portapres® Model 2). Cardiovascular

26 function was also measured in rest. Experimental design was double-blind, placebo-controlled,

27 randomized and cross-over (wash-out 4 wks). Data was analysed with two-tailed t-tests and 2-

28 way ANOVA and significance accepted at $\mathrm{p}<0.05$. Plasma lactate was lower at $40 \%, 50 \%, 60 \%$

29 and $70 \%$ of maximum power by $27 \%, 22 \%, 17 \%$ and $13 \%$. Intensity at $4 \mathrm{mmol} \cdot \mathrm{L}^{-1} \mathrm{OBLA}$ was

$306 \%$ higher with blackcurrant without effect on heart rate and oxygen uptake. Maximum values of

31 oxygen uptake, heart rate and power were not affected by blackcurrant, but obtained with $14 \%$

32 lower lactate. In rest, blackcurrant increased stroke volume and cardiac output by $25 \%$ and $26 \%$,

33 and decreased total peripheral resistance by $16 \%$, with no changes in blood pressure and heart

34 rate. Cardiovascular responses during exercise at 40\%, 50\%, 60\%, $70 \%$ and $80 \%$ intensity were

35 not affected. Sujon New Zealand blackcurrant powder affects lactate production and/or clearance

36 during exercise. Sujon New Zealand blackcurrant powder affects physiological and

37 cardiovascular responses in rest and during exercise that may have implications for exercise

38 performance.

40 Key words: Plasma lactate; cardiovascular function, New Zealand blackcurrant

\section{INTRODUCTION}

Blackcurrant is a rich source for anthocyanin, a flavonoid that has attracted attention 45 recently for human health benefits such as reduced risks for myocardial infarction (Cassidy et al., 46 2013) and type 2 diabetes (Wedick et al., 2012), inhibition of the proliferation of cancer cells As accepted for publication, http://journals.humankinetics.com/ijsnem 
As accepted for publication, http://journals.humankinetics.com/ijsnem

47 (Bishayee et al., 2010), anti-inflammatory effects (Zhu et al., 2013), and anti-oxidant activity (De

48 la Cruz et al., 2013). Ergogenic aids with anti-inflammatory and anti-oxidant activity counteract

49 potentially negative responses to exercise. For example, catechins, shiitake, resveratrol,

50 quercetin, montmorency cherries, that are known ergogenic aids with anti-inflammatory and

51 anti-oxidant properties, have been examined primarily for their effectiveness on exercise

52 recovery (Haramizu et al., 2011; McAnulty et al., 2013; Zembron-Lacny et al., 2013). In

53 addition, anthocyanin-containing fruits and berries, including blackcurrant, were examined for

54 post-exercise effects on immune and functional responses (montmorency cherry juice: Bowtell et

55 al., 2011; tart cherry juice: Connolly et al., 2006; blackcurrant extract: Lyall et al., 2009;

56 blueberry: McLeay et al., 2012). It is not known whether the effects are caused by intake of a

57 total amount of anthocyanins or amount of specific anthocyanins. However, the effectiveness of

58 such ergogenic aids on the physiological responses during exercise has not been addressed.

59 Blackcurrant has an effect on human cardiovascular responses during activity. Peripheral

60 blood flow was increased by $22 \%$ during typing work in humans (Matsumoto et al., 2005),

61 potentially by anthocyanin-induced vasorelaxation and vasodilation as shown in thoracic aortic

62 rings in male Wistar rats (Ziberna et al., 2013). In intact rat aortic rings (i.e. with functional

63 endothelium), anthocyanins induced relaxation by $37 \%$, possibly by involvement of the

64 purinergic pathway producing nitric oxide (Mendes et al., 2003). Edirisinghe et al (2011)

65 provided evidence using human umbilical vein endothelial cells that blackcurrant concentrate

66 activated eNOS via the Akt/PI3 kinase pathway. In addition, Nakamura et al (2002) observed

67 that blackcurrant concentrate enhanced the synthesis of nitric oxide and induced dose-dependent

68 relaxation up to $80 \%$. In this study, removal of the endothelium blunted the effect of the

69 anthocyanins, supporting endothelial function to be affected. Caution is required, however, to

As accepted for publication, http://journals.humankinetics.com/ijsnem 
As accepted for publication, http://journals.humankinetics.com/ijsnem

70 generalize from in vitro exposure of arteries with blackcurrant to an in-vivo condition in humans.

71 However, dietary intake of anthocyanin intake was associated with lower arterial stiffness and

72 central blood pressure in women (Jennings et al., 2012). All together, these studies provide the

73 evidence that may support an effect of anthocyanin on cardiovascular responses in rest and

74 during exercise.

75 An anthocyanin effect on cardiovascular responses during exercise may influence the

76 delivery of substrates and removal of metabolic products of skeletal muscles. It is a classic

77 observation, for example, that during exercise of incremental intensity, blood lactate accumulates

78 in an exponential fashion as a consequence of production and removal mechanisms. An increase

79 in peripheral blood flow by anthocyanin may benefit the removal mechanisms of lactate as

80 uptake may be enhanced by liver, heart, kidney and skeletal muscles. As such, intracellular

81 lactate oxidation (Gladden, 2008) and lactate conversion into glucose may be enhanced and

82 could potentially lead to glycogen sparing (Emhoff et al., 2013). Increases in peripheral blood

83 flow may also affect the oxygen consumed during exercise and potentially reduce effects of

84 peripheral fatigue mechanisms and beneficial for exercise performance. The effects of

85 blackcurrant on the lactate responses during incremental exercise and maximum oxygen uptake

86 have not been examined.

87 Lactate threshold or absolute lactate values during incremental exercise and maximum

88 oxygen uptake are recognized indicators of the ability for endurance performance [for a review

89 see (Bentley et al., 2007)]. An increased peripheral blood flow may affect lactate clearance and

90 oxygen delivery influencing the exercise intensity at lactate indicators (e.g. onset of blood lactate

91 accumulation (OBLA) at $4 \mathrm{mmol} \cdot \mathrm{L}^{-1}$ ), maximum oxygen uptake and the cardiovascular

92 responses in rest and during exercise. Therefore, the primary objective was to examine the effect

As accepted for publication, http://journals.humankinetics.com/ijsnem 
As accepted for publication, http://journals.humankinetics.com/ijsnem

93 of 7 days supplementation with Sujon New Zealand blackcurrant powder on the blood plasma

94 lactate curve and aerobic capacity of trained triathletes. Second objective was to examine

95 whether such supplementation would affect the cardiovascular responses at rest and exercise.

\section{METHODS}

99 Healthy male $(n=8)$ and female $(n=5)$ triathletes with $>3$ yrs triathlon experience (age: $38 \pm 8$ yrs, 100 height: $174 \pm 5 \mathrm{~cm}$, body mass: $71 \pm 9 \mathrm{~kg}, \mathrm{BMI}: 23 \pm 2, \mathrm{BF} \%: 19 \pm 5 \%$, mean $\pm \mathrm{SD}$ ) were recruited

101 from local triathlon clubs and volunteered without payment. Participants provided written

102 informed consent after explanation of the experimental procedures, potential risks and benefits.

103 Ethical approval was obtained from the University of Chichester Ethics Research Committee. In

104 brief, participants visited for one familiarization and two experimental testing sessions.

105 Familiarization consisted of practicing all experimental procedures and recording of baseline

106 subject characteristics [i.e. age, height, body mass, BMI, body fat (\%) (Tanita BC418 segmental

107 body composition analyser)]. Participants attended for two experimental visits to perform cycling

108 protocols to examine the effectiveness of 7 days of intake of Sujon New Zealand blackcurrant

109 powder [NZBC, 6g/day (138.6 mg anthocyanins) or placebo (PBO)]. Placebo was a

110 commercially available blackcurrant juice with British blackcurrants containing likely about 3-4

111 mg anthocyanins per dose (Mattila et al., 2011). We were not able to quantify the bioavailability

112 of anthocyanins in the blood. Optimal dosing strategy of New Zealand blackcurrant powder is

113 not known and the dose was according manufacturers guidelines. Studies on the effectiveness of

114 berry juices applied also multiple days of intake before exercise testing (e.g. 8 days: Bowtell et

115 al., 2011; 4 days: Connolly et al., 2006; 6 days: Howatson et al., 2010). The experimental design

As accepted for publication, http://journals.humankinetics.com/ijsnem 
As accepted for publication, http://journals.humankinetics.com/ijsnem

116 was double blind, randomized, placebo-controlled, and cross-over with drinks provided in

117 unlabelled bottles. Participants recorded their dietary intake for $48 \mathrm{hr}$ before attending the first

118 experimental visit and followed the identical dietary pattern before the second visit. Participants

119 were instructed not to exercise and consume alcohol $24 \mathrm{hr}$ before each visit, be well-rested and

120 hydrated on arrival, and not take other supplements that add further nutritional value to the

121 normal diet. For the experimental visits, participants visited 2-3 hr postprandial, after a light

122 breakfast of toast and water and intake of the final supplement. All testing occurred in a

123 temperature controlled $\left(\sim 18^{\circ} \mathrm{C}\right)$ exercise physiology laboratory. The sequence of testing during

124 an experimental visit comprised of 20 min recording of resting cardiovascular function followed

125 by the cycling protocol for lactate responses with recording of physiological and cardiovascular

126 responses. Then, following a 30 min rest, the cycling protocol for maximum oxygen uptake was

127 performed.

129 Experimental procedures

$130 \quad$ Incremental cycling protocols

131 The incremental cycling protocol for lactate responses consisted of 4 min stages with 2

132 min recovery, start power $50 \mathrm{~W}$ with $30 \mathrm{~W}$ increments [adapted from (González-Haro et al.,

133 2007)], with termination by obtaining a plasma lactate response close to or over $4.0 \mathrm{mmol} \cdot \mathrm{L}^{-1}$.

134 The maximum oxygen uptake protocol had a start power $50 \mathrm{~W}$ for $4 \mathrm{~min}$ with $30 \mathrm{~W} \cdot \mathrm{min}^{-1}$

135 increments [adapted from (Bailey et al., 2009)] with termination by voluntary exhaustion.

136 Cycling protocols were performed at self-selected pedal cadence (70-90 rpm) on an ergometer

137 (SRM ergometer, SRM International, Germany). In the last minute of each stage during the

138 cycling protocol for lactate, expired air was collected using the Douglas bag technique and heart

As accepted for publication, http://journals.humankinetics.com/ijsnem 
As accepted for publication, http://journals.humankinetics.com/ijsnem

139 rate (Polar Vantage NV, Polar Electro Oy, Kempele, Finland) recorded. Expired air was analysed

140 with three-point calibrated Servomex gas analysers (Servoflex MiniMP, 5200 Multipurpose) and

141 volume measured (Harvard dry gas meter). Gas volumes were calculated using Haldane

142 transformation and standardisation to STPD conditions with consideration of fractions of oxygen

143 and carbon dioxide of inspired air. Blood samples for analysis of plasma lactate were taken using

144 finger-prick method immediately after each stage and 3 min after voluntary exhaustion during

145 the maximum oxygen uptake test (2300 STAT Plus ${ }^{\mathrm{TM}}$ analyser, YSI Life Sciences, Yellow

146 Springs, USA). In at least the last 4 minutes of the maximum oxygen uptake protocol, expired

147 gases were collected in 45 seconds samples with 30 seconds samples in the last minute using

148 Douglas bags (Plysu Protection Systems Limited, Milton Keynes, UK). A blood sample was

149 taken 3 minutes after the end of the test.

151 Cardiovascular measurements

152 Cardiovascular responses were recorded using a beat-to-beat blood pressure monitoring 153 system (Portapres @ Model 2, Finapres Medical Systems BV, Amsterdam, The Netherlands) in 154 rest and during the incremental cycling protocol for lactate responses. The Portapres® Model 2 is 155 a beat-to-beat finger pressure analyser that allows the non-invasive continuous measurement of 156 hemodynamic parameters. The Portapres has shown reliability for the relative changes in cardiac 157 output (Sugawara et al., 2003). Clear outliers in recorded data were removed. The finger cuff 158 was positioned around the same finger of the hand of the left arm. For the resting condition, 159 participants were in a supine position for $20 \mathrm{~min}$. Cardiovascular measures in rest were averaged 160 over 10 consecutive beats, with the lowest systolic blood pressure (BP) and associated measures 161 analysed. For the exercise condition, cardiovascular measures were averaged for the last minute As accepted for publication, http://journals.humankinetics.com/ijsnem 
As accepted for publication, http://journals.humankinetics.com/ijsnem

162 of each stage in which participants held the left arm in front of their chest to enable recording of

163 the signal with less noise. The following parameters were derived: stroke volume, cardiac output,

164 systolic blood pressure, diastolic blood pressure, mean arterial pressure, and total peripheral

165 resistance (Beatscope 1.1a., Finapres Medical Systems BV, Amsterdam, The Netherlands).

166

167 Supplementation protocol

168 Participants were provided with a 4 day supply of Sujon New Zealand blackcurrant powder (24

169 gram in $571 \mathrm{~mL}$ of water) followed by 3 day supply (18 gram in $429 \mathrm{~mL}$ of water), dissolved in

170 opaque bottles. Sujon New Zealand blackcurrant powder contains $138.6 \mathrm{mg}$ anthocyanin, $49 \mathrm{mg}$

171 Vit C and 5.2 gram of carbohydrates per 6 gram serving. Per serving, total phenolic content was

$172271.6 \mathrm{mg}$. Placebo was a commercially available low-calorie blackcurrant juice drink (Ribena

173 Blackcurrant), containing $32 \mathrm{mg}$ Vit $\mathrm{C}$ and $~ 1.6$ gram of carbohydrates per $250 \mathrm{ml}$ serving.

174 Participants were instructed to take the supplement or placebo with breakfast with the last intake

175 about 2 hrs before an experimental visit. Participants were provided with a marked plastic cup to

176 ensure equal daily intake over a 7-day period. Wash-out period was 4 weeks (Jin et al., 2011).

177

178 Statistical analysis.

179 The mathematical relationship between cycling power and lactate for each individual was

180 determined with a third degree polynomial using lactate analysis software (Newell et al., 2007)

$181\left[\mathrm{R}^{2}\right.$ values of $0.9868 \pm 0.0174$ (placebo) and $0.9871 \pm 0.0198$ (Sujon New Zealand blackcurrant

182 powder)] and calculated at 30\%, 40\%, 50\%, 60\%, $70 \%$ and $80 \%$ of maximal cycling power

183 obtained with the maximum oxygen uptake cycling test. Intensity, oxygen uptake and heart rate

184 were calculated at a lactate rise of $1 \mathrm{mmol} \cdot \mathrm{L}^{-1}$ and a lactate value of $4 \mathrm{mmol} \cdot \mathrm{L}^{-1}(\mathrm{OBLA}$, onset of

As accepted for publication, http://journals.humankinetics.com/ijsnem 
As accepted for publication, http://journals.humankinetics.com/ijsnem

185 blood plasma lactate accumulation) using the lactate analysis software. Cardiovascular responses

186 during exercise were taken for the stage closest to $40 \%, 50 \%, 60 \%, 70 \%$ and $80 \%$ of maximum

187 oxygen uptake resulting in intensity for placebo of $41 \pm 5 \%, 51 \pm 4 \%, 60 \pm 6 \%, 70 \pm 3 \%$, and $79 \pm 4 \%$

188 and for the Sujon New Zealand blackcurrant powder condition $41 \pm 3 \%, 48 \pm 2 \%, 57 \pm 3 \%, 67 \pm 6 \%$,

189 and $80 \pm 4 \%$. Data for 3 participants for the cardiovascular responses during exercise was

190 excluded due to the inability of recording of a clean signal. A sample size of 9 would allow

191 detection of a 20\% difference in cardiac output at rest (power: 0.80: $\alpha$-level: 0.05). Resting

192 cardiovascular data passed normality check with D’Agostino and Pearson omnibus normality test

193 (Prism v5.04, Graphpad Software Inc.) to allow paired t-tests. Lactate and cardiovascular

194 responses during exercise were analysed with 2-way ANOVA and post hoc t-tests to examine

195 condition effects at each intensity. Significance was accepted at $\mathrm{p}<0.05$.

197 RESULTS

198 Lactate responses

199 The intensity at $1 \mathrm{mmol} \cdot \mathrm{L}^{-1}$ lactate rise was $4 \%$ higher with Sujon New Zealand blackcurrant 200 powder (PBO: $184 \pm 52$, NZBC: $192 \pm 52 \mathrm{~W}$, range -2 to $14 \%, 8$ participants showed an increase 201 and 1 no change) $(\mathrm{p}=0.02)$. In both conditions at a $1 \mathrm{mmol} \cdot \mathrm{L}^{-1}$ lactate rise, there were no

202 differences in heart rate (PBO: $141 \pm 16$, NZBC: $141 \pm 14 \mathrm{~b} \cdot \mathrm{min}^{-1}, \mathrm{p}=0.83$ ) or oxygen uptake 203 (PBO: $2.54 \pm 0.66$, NZBC: $2.49 \pm 0.63 \mathrm{~L} \cdot \mathrm{min}^{-1}, \mathrm{p}=0.41$ ). The intensity at $4 \mathrm{mmol} \cdot \mathrm{L}^{-1} \mathrm{OBLA}$ was

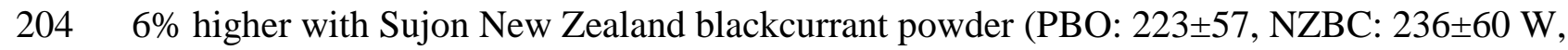
205 range -5 to $22 \%, 11$ participants showed an increase and 1 no change) $(\mathrm{p}=0.007)$ (Figure 1$)$. In 206 both conditions at $4 \mathrm{mmol} \cdot \mathrm{L}^{-1} \mathrm{OBLA}$, there were no differences in heart rate (PBO: $159 \pm 7$, 207 NZBC: $164 \pm 10 \mathrm{~b} \cdot \mathrm{min}^{-1}, \mathrm{p}=0.13$ ) or oxygen uptake (PBO: $2.91 \pm 0.73, \mathrm{NZBC}: 2.96 \pm 0.71 \mathrm{~L} \cdot \mathrm{min}^{-1}$, As accepted for publication, http://journals.humankinetics.com/ijsnem 
As accepted for publication, http://journals.humankinetics.com/ijsnem

$208 \mathrm{p}=0.31$ ). Plasma lactate was lower at 40\% (PBO: $1.24 \pm 0.52$, NZBC: $0.91 \pm 0.46 \mathrm{mmol} \cdot \mathrm{L}^{-1}$,

$209 \mathrm{p}=0.001$ ), 50\% (PBO: $\left.1.58 \pm 0.78, \mathrm{NZBC}: 1.23 \pm 0.64 \mathrm{mmol} \mathrm{L}^{-1}, \mathrm{p}=0.002\right), 60 \%(\mathrm{PBO}: 2.29 \pm 0.96$,

210 NZBC: $1.91 \pm 0.87 \mathrm{mmol} \cdot \mathrm{L}^{-1}, \mathrm{p}=0.001$ ) and $70 \%$ (PBO: $3.52 \pm 1.10$, NZBC: $3.08 \pm 1.21 \mathrm{mmol} \cdot \mathrm{L}^{-1}$,

$211 \mathrm{p}=0.004$ ) of maximum power, decreases of 27\%, 22\%, 17\% and 13\%, respectively (Figure 2).

212

\section{Maximum oxygen uptake}

214 There was no effect on maximum values of oxygen uptake (PBO: $49.1 \pm 6.2$, NZBC: $49.7 \pm 6.1$

$\left.215 \mathrm{~mL} \cdot \mathrm{kg}^{-1} \cdot \mathrm{min}^{-1}, \mathrm{p}=0.16\right)$, power (PBO: $\left.305 \pm 68, \mathrm{NZBC}: 307 \pm 62 \mathrm{~W}, \mathrm{p}=0.66\right)$ or heart rate (PBO:

$216172 \pm 10$, NZBC: $\left.172 \pm 11 \mathrm{~b} \cdot \mathrm{min}^{-1}, \mathrm{p}=0.68\right)$. However, maximum oxygen uptake with Sujon New

217 Zealand blackcurrant powder was obtained with 14\% lower lactate values (measured 3-min after

218 exhaustion; PBO: 7.85 \pm 1.69 , NZBC: $6.79 \pm 1.51 \mathrm{mmol} \cdot \mathrm{L}^{-1}$, range -27 to $48 \%$, 10 participants

219 showed a decrease and 1 no change) $(\mathrm{p}=0.02)$ (Figure 3$)$.

220

221 Cardiovascular function in rest

222 There were no differences in systolic BP (PBO: $121 \pm 23$, NZBC: $120 \pm 23 \mathrm{mmHg}, \mathrm{p}=0.92$ ),

223 diastolic BP (PBO: 69 \pm 16 , NZBC: $63 \pm 14 \mathrm{mmHg}, \mathrm{p}=0.12$ ), mean arterial BP (PBO: 86 \pm 18 ,

224 NZBC: $82 \pm 18 \mathrm{mmHg}, \mathrm{p}=0.33$ ), and heart rate (PBO: $58 \pm 9, \mathrm{NZBC}: 59 \pm 10$ beats $\cdot \mathrm{min}^{-1}, \mathrm{p}=0.95$ ).

225 Stroke volume (PBO: 82 \pm 23 , NZBC: $99 \pm 25 \mathrm{~mL}, \mathrm{p}=0.006)$ and cardiac output (PBO: 4.8 \pm 1.6 ,

226 NZBC: $5.8 \pm 1.7 \mathrm{~L} \cdot \mathrm{min}^{-1}, \mathrm{p}=0.015$, Figure $4 \mathrm{~A}$ ) were increased by $25 \%$ and $26 \%$, respectively.

227 There was a 16\% lower total peripheral resistance (PBO: $20.2 \pm 8.9$, NZBC: $15.2 \pm 5.3 \mathrm{mmHg} \cdot \mathrm{L}$

$\left.22{ }^{1} \cdot \mathrm{min}^{-1}, \mathrm{p}=0.05\right)$ (Figure 4B). The changes in resting cardiovascular function were observed in 10 229 participants.

As accepted for publication, http://journals.humankinetics.com/ijsnem 
As accepted for publication, http://journals.humankinetics.com/ijsnem

\section{Cardiovascular responses during exercise}

At each intensity, there were no differences in diastolic $\mathrm{BP}(\mathrm{p}=0.56)$, systolic $\mathrm{BP}(\mathrm{p}=0.76)$, mean arterial blood pressure $(\mathrm{p}=0.54)$, heart rate $(\mathrm{p}=0.78)$, stroke volume $(\mathrm{p}=0.88)$, cardiac output $(\mathrm{p}=0.97)$ and total peripheral resistance $(\mathrm{p}=0.58)$ between placebo and New Zealand blackcurrant at each intensity (Table 1).

\section{DISCUSSION}

The present study provides evidence for an effect on the physiological responses during exercise and resting cardiovascular function by short duration (1 week) intake of an anthocyanincontaining supplement. Short-term supplementation with Sujon New Zealand blackcurrant powder shifted the lactate curve during exercise, allowed maximum oxygen uptake with lower lactate, increased resting cardiac output and stroke volume and decreased resting total peripheral resistance. No effects were observed for cardiovascular responses during exercise. In addition, no effects were observed for functional capacity (i.e. power at maximum oxygen uptake), thus the practical implications of the supplement intervention are still unclear.

As far as we know, the substantial combined downward and rightward shift of the lactate curve in the present study with Sujon New Zealand blackcurrant powder has not been reported by other supplement intake. It is well known that the downward and rightward shift of the lactate curve results from physiological and metabolic adaptations by endurance training (Faude et al., 2009) and high-intensity training (Evertsen et al., 2001); in our study, the right-ward shift of the lactate curve resulted that OBLA was obtained at a $6 \%$ higher cycling intensity. A delay in OBLA may have beneficial implications for endurance athletes as it would allow prolonged high

As accepted for publication, http://journals.humankinetics.com/ijsnem 
As accepted for publication, http://journals.humankinetics.com/ijsnem

254 intensity exercise during competition and endurance exercise training. In addition, a delay in

255 OBLA could be predictive for an enhancement of cycling endurance performance. However,

256 supplementation with Sujon New Zealand blackcurrant powder did not replicate other common

257 endurance training adaptations in physiological responses because heart rate and oxygen uptake

258 at OBLA, for example, were not affected. Other supplements have been reported to be able to

259 shift the lactate curve right-ward. For example, recreationally active men delayed OBLA after 28

260 days of beta-alanine supplementation but with increased absolute heart rate as a percentage of

261 maximum values (Jordan et al., 2010). In endurance-trained cyclists, OBLA with beta-hydroxy

262 betamethylbutarate and leucine was delayed by $9.1 \%$ and $2.1 \%$, respectively (Vukovich \&

263 Dreifort, 2001). Neither of these studies reported a downward shift of the lactate curve.

264 Therefore, the mechanisms causing delayed OBLA in previous studies by supplementation

265 (Jordan et al., 2010) or training (Evertsen et al., 2001) are possibly explained by different

266 physiological mechanisms that delayed the OBLA and blood lactate accumulation in the present

267 study. Blood lactate accumulation results from an imbalance between lactate appearance and

268 removal mechanisms (Brook, 1985). Our data provides evidence for the following acute

269 physiological adaptations with short-term anthocyanin supplementation. First, short-term

270 supplementation with anthocyanin seems to alter the balance of lactate appearance and removal

271 mechanisms to blood lactate accumulation. Second, it seems that the alteration of the balance of

272 factors contributing to blood lactate accumulation is/are intensity-dependent with exercise at

273 relatively low intensity to be more affected. The lactate appearance may have been altered by an

274 anthocyanin effect on substrate oxidation such that there was potentially an increased

275 contribution of fat oxidation at relatively low intensities. Future work should address whether

276 substrate oxidation is altered with blackcurrant supplementation. The removal mechanisms may

As accepted for publication, http://journals.humankinetics.com/ijsnem 
As accepted for publication, http://journals.humankinetics.com/ijsnem

277 have been enhanced by an increase in peripheral blood flow. An increase in peripheral blood

278 flow was reported by Matsumoto et al (2005), in typing work, a physical activity performed at

279 relatively low intensity. We were not able to quantify the contribution of lactate appearance and

280 removal mechanism towards reduced lactate at low and moderate exercise intensities. However,

281 increased peripheral blood flow by anthocyanin vasodilating effects may have contributed to

282 increased lactate clearance.

283

Maximum oxygen uptake was not affected by blackcurrant intake but obtained with

284 lower lactate values. Although the protocols for obtaining the lactate curve and maximum

285 oxygen uptake were different in stage duration, the lower lactate value may indicate reduced

286 contribution of anaerobic glycolysis needed to reach exhaustion or increased clearance

287 immediately following exercise and being at rest.

At rest (but without preceding exercise), total peripheral resistance was reduced with

289 blackcurrant supplementation. As far as we know, there is no evidence that anthocyanins or their

290 metabolites can reduce sympathetic drive, but if this had happened, resting heart rate would have

291 been affected and that was not the case. In humans, it was observed that orally provided

292 anthocyanins (320 mg containing 17 different anthocyanins from bilberry and blackcurrant)

293 induced an increase in brachial flow-mediated dilation of about $10 \% 2 \mathrm{hr}$ after intake in

294 hypercholesterolemic individuals (Zhu et al., 2011). The dose in our study was $138.6 \mathrm{mg}$ of total 295 anthocyanins in Sujon New Zealand blackcurrant powder. In addition, Zhu et al (2011) provided

296 the anthocyanin in capsule form bypassing possible anthocyanin-dependent degradation in mouth

297 saliva (Kamonpatana et al., 2012; Kamonpatana et al., 2014) by powder intake in the present

298 study, although potential effects are small due to the time needed for degradation by saliva. It is

299 possible that in our study, blackcurrant anthocyanins (or its metabolites) increased nitric oxide

As accepted for publication, http://journals.humankinetics.com/ijsnem 
As accepted for publication, http://journals.humankinetics.com/ijsnem

300 production (Xu et al., 2004; Ziberna et al., 2013) leading to a decrease in total peripheral

301 resistance. However, the reciprocal changes of reduced total peripheral resistance and increased

302 cardiac output (by increased stroke volume), but no changes in resting heart rate and blood

303 pressure suggests probably more complex hemodynamic mechanisms. For example, increased

304 resting cardiac output could normally result from an increase in resting heart rate but this was not

305 the case.

306 There are some limitations of the present study. First, our understanding of the

307 mechanisms of the effects by oral intake of Sujon New Zealand blackcurrant powder requires

308 information on the bioavailability of anthocyanins and metabolites. In addition, work is required

309 to examine the mechanisms of physiological effects by anthocyanins and metabolites in in-vivo

310 exercise models. Second, we did not consider sex of the participants, and differences in substrate

311 oxidation, for example, may affect the observed lactate responses. Third, we do not know

312 whether the observed effects were due to the duration of the intake. Fourth, maximum oxygen

313 uptake values are likely indicative of moderately trained individuals and effectiveness in more

314 trained populations is recommended.

315 In summary, effects of Sujon New Zealand blackcurrant powder for the endurance

316 athletes during exercise on the lactate curve and resting cardiovascular function may initiate a

317 new direction in applied sports nutrition research. There is scope to focus on the physiological,

318 metabolic and performance effects of New Zealand blackcurrant in different exercise modalities.

319 Intake of Sujon New Zealand blackcurrant powder was associated with 1) a downward and

320 rightward shift of the lactate curve during cycling over a wide range of exercise intensities, 2)

321 lower plasma lactate at aerobic capacity suggesting increased lactate clearance or altered

As accepted for publication, http://journals.humankinetics.com/ijsnem 
As accepted for publication, http://journals.humankinetics.com/ijsnem

322 substrate oxidation, 3) improved cardiovascular function at rest. These findings may have

323 implications for training practice, aerobic performance and recovery of endurance athletes.

325 Acknowledgement

326 Funding for this study was provided by the University of Chichester, Health Currancy Ltd

327 (United Kingdom) and Gibb Holdings (Nelson) Limited (New Zealand).

330 References

332 Bailey, S.J., Winyard, P., Vanhatalo, A. Blackwell, J.R., Dimenna, F.J., Wilkerson, D.P., Tarr, J., 333 Benjamin, N., \& Jones A.M. (2009). Dietary nitrate supplementation reduces the O2 cost of low334 intensity exercise and enhances tolerance to high-intensity exercise in humans. Journal of 335 Applied Physiology (1985), 107, 1144-1155. doi: 10.1152/japplphysiol.00722.2009.

336 Bentley, D.J., Newell, J., \& Bishop, D. (2007). Incremental exercise test design and analysis:

337 implications for performance diagnostics in endurance athletes. Sports Medicine, 37, 575-586.

338 doi: 10.2165/00007256-200737070-00002.

339 Bishayee, A., Háznagy-Radnai, E., Mbimba, T., Sipos, P., Morazzoni, P., Darvesh, A.S., Bhatia, 340 D., \& Hohmann, J. (2010). Anthocyanin-rich black currant extract suppresses the growth of 341 human hepatocellular carcinoma cells. Natural Product Communications, 5, 1613-1618. doi: 34221121259.

As accepted for publication, http://journals.humankinetics.com/ijsnem 
As accepted for publication, http://journals.humankinetics.com/ijsnem

343 Bowtell, J.L., Sumners, D.P., Dyer, A., Fox, P., \& Mileva, K.N. (2011). Montmorency cherry

344 juice reduces muscle damage caused by intensive strength exercise. Medicine \& Science in

345 Sports \& Exercise, 43, 1544-1551. doi: 10.1249/MSS.0b013e31820e5adc.

346 Brooks, G.A. (1985). Anaerobic threshold: review of the concept and directions for future

347 research. Medicine \& Science in Sports \& Exercise, 17, 22-34.

348 Cassidy, A., Mukamal, K.J., Liu, L., Franz, M., Eliassen, A.H., \& Rimm, E.B. (2013). High

349 anthocyanin intake is associated with a reduced risk of myocardial infarction in young and

350 middle-aged women. Circulation, 127, 188-196. doi:

351 10.1161/CIRCULATIONAHA.112.122408.

352 Connolly, D.A., McHugh, M.P., Padilla-Zakour, O.I., Carlson, L., \& Sayers, S.P. (2006).

353 Efficacy of a tart cherry juice blend in preventing the symptoms of muscle damage. British

354 Journal of Sports Medicine, 40, 679-683. doi: 10.1136/bjsm.2005.025429.

355 De la Cruz, A.A., Hilbert, G., Mengin, V. Rivière, C., Ollat, N., Vitrac, C., Bordenave,

356 L., Decroocq, S., Delaunay, J.C., Mérillon, J.M., Monti, J.P., Gomès, E., \& Richard, T. (2013).

357 Anthocyanin phytochemical profiles and anti-oxidant activities of Vitis candicans and Vitis

358 doaniana. Phytochemical Analysis, 24, 446-452. doi: 10.1002/pca.2447.

359 Edirisinghe, I., Banaszewski, K., Cappozzo, J., McCarthy, D., \& Burton-Freeman, B.M. (2011).

360 Effect of black currant anthocyanins on the activation of endothelial nitric oxide synthase

361 (eNOS) in vitro in human endothelial cells. Journal of Agricultural and Food Chemistry, 59,

362 8616-8624. doi: 10.1021/jf201116y.

363 Emhoff, C.A., Messonnier, L.A., Horning, M.A., Fattor, J.A., Carlson, T.J., \& Brooks, G.A.

364 (2013). Direct and indirect lactate oxidation in trained and untrained men. Journal of Applied

365 Physiology (1985), 115, 829-838. doi: 10.1152/japplphysiol.00538.2013.

As accepted for publication, http://journals.humankinetics.com/ijsnem 
As accepted for publication, http://journals.humankinetics.com/ijsnem

366 Evertsen, F., Medbø, J.I., \& Bonen, A. (2001). Effect of training intensity on muscle lactate

367 transporters and lactate threshold of cross-country skiers. Acta Physiologica Scandinavica, 173,

368 195-205. doi: 10.1046/j.1365-201X.2001.00871.x

369 Faude, O., Kindermann, W., \& Meyer, T. (2009). Lactate threshold concepts: how valid are

370 they? Sports Medicine, 39, 469-490. doi: 10.2165/00007256-200939060-00003.

371 Gladden, L.B. (2008). 200th anniversary of lactate research in muscle. Exercise and Sport

372 Sciences Reviews, 36, 109-115. doi: 10.1097/JES.0b013e31817c0038.

373 González-Haro, C., Galilea, P.A., Drobnic, F., \& Escanero, J.F. (2007). Validation of a field test

374 to determine the maximal aerobic power in triathletes and endurance cyclists. British Journal of

375 Sports Medicine, 41, 174-179. doi: 10.1136/bjsm.2006.031310.

376 Haramizu, S., Ota, N., Hase, T., \& Murase, T. (2011). Catechins attenuate eccentric exercise-

377 induced inflammation and loss of force production in muscle in senescence-accelerated mice.

378 Journal of Applied Physiology (1985), 111, 1654-1663. doi: 10.1152/japplphysiol.01434.2010.

379 Howatson, G., McHugh, M.P., Hill, J.A., Brouner, J., Jewell, A.P., van Someren, K.A., Shave,

380 R.E., \& Howatson, S.A. (2010). Influence of tart cherry juice on indices of recovery following

381 marathon running. Scandinavian Journal of Medicine \& Science in Sports, 20, 843-852. doi:

$38210.1111 / \mathrm{j} .1600-0838.2009 .01005 . x$.

383 Jennings, A., Welch, A.A., Fairweather-Tait, S.J., Kay, C., Minihane, A.M., Chowienczyk, P.,

384 Jiang, B., Cecelja, M., Spector, T., Macgregor, A., \& Cassidy, A. (2012). Higher anthocyanin

385 intake is associated with lower arterial stiffness and central blood pressure in women. The

386 American Journal of Clinical Nutrition, 96, 781-788. doi: 10.3945/ajcn.112.042036.

387 Jin, Y., Alimbetov, D., George, T., Gordon, M.H., \& Lovegrove, J.A. A randomised trial to

As accepted for publication, http://journals.humankinetics.com/ijsnem 
As accepted for publication, http://journals.humankinetics.com/ijsnem

388 investigate the effects of acute consumption of a blackcurrant juice drink on markers of vascular 389 reactivity and bioavailability of anthocyanins in human subjects. (2011). European Journal of

390 Clinical Nutrition, 65, 849-856. doi: 10.1038/ejen.2011.55.

391 Jordan, T., Lukaszuk, J., Misic, M., \& Umoren, J. (2010). Effect of beta-alanine supplementation

392 on the onset of blood lactate accumulation (OBLA) during treadmill running: Pre/post 2

393 treatment experimental design. Journal of the International Society of Sports Nutrition, 7, 20.

394 doi: 10.1186/1550-2783-7-20.

395 Kamonpatana, K., Failla, M.L., Kumar, P.S., \& Giusti, M.M. (2014). Anthocyanin structure

396 determines susceptibility to microbial degradation and bioavailability to the buccal mucosa.

397 Journal of Agricultural and Food Chemistry, 62, 6903-6910. doi: 10.1021/jf405180k.

398 Kamonpatana, K., Giusti, M.M., Chitchumroonchokchai, C., MorenoCruz, M., Riedl, K.M.,

399 Kumar, P., \& Failla, M.L. (2012). Susceptibility of anthocyanins to ex vivo degradation in

400 human saliva. Food Chemistry, 135, 738-747. doi: 10.1016/j.foodchem.2012.04.110.

401 Lyall, K.A., Hurst, S.M., Cooney, J., Jensen, D., Lo, K., Hurst, R.D., \& Stevenson, L.M. (2009).

402 Short-term blackcurrant extract consumption modulates exercise-induced oxidative

403 stress and lipopolysaccharide-stimulated inflammatory responses. American Journal of

404 Physiology Regul Integr Comp Physiol, 297, R70-81. doi: 10.1152/ajpregu.90740.2008.

405 Mattila, P.H., Hellström, J., McDougall, G., Dobson, G., Pihlava, J.M., Tiirikka, T.,

406 Stewart, D., \& Karjalainen, R. (2011). Polyphenol and vitamin C contents in European

407 commercial blackcurrant juice products. Food Chemistry, 127, 1216-1223. doi:

$408 \quad$ 10.1016/j.foodchem.2011.01.129.

409 Matsumoto, H., Takenami, E., Iwasaki-Kurashige, K., Osada, T., Katsumura, T., \& Hamaoka, T.

410 (2005). Effects of blackcurrant anthocyanin intake on peripheral muscle circulation during typing As accepted for publication, http://journals.humankinetics.com/ijsnem 
As accepted for publication, http://journals.humankinetics.com/ijsnem

411 work in humans. European Journal Applied Physiology, 94, 36-45. doi: 10.1007/s00421-004-

412 1279-y.

413 McAnulty, L.S., Miller, L.E., Hosick, P.A., Utter, A.C., Quindry, J.C., \& McAnulty, S.R. (2013).

414 Effect of resveratrol and quercetin supplementation on redox status and inflammation after

415 exercise. Applied Physiology, Nutrition, and Metabolism, 38, 760-765. doi: 10.1139/apnm-2012-

4160455.

417 McLeay, Y., Barnes, M.J., Mundel, T., Hurst, S.M., Hurst, R.D., Stannard, S.R. (2012). Effect of

418 New Zealand blueberry consumption on recovery from eccentric exercise-induced muscle

419 damage. Journal of the International Society of Sports Nutrition, 9, 19. doi: 10.1186/1550-2783-

$420 \quad 9-19$.

421 Mendes, A., Desgranges, C., Chèze, C., Vercauteren, J., \& Freslon, J.L. (2003). Vasorelaxant

422 effects of grape polyphenols in rat isolated aorta. Possible involvement of a purinergic pathway.

423 Fundamental \& Clinical Pharmacology, 17, 673-681. DOI: 10.1046/j.1472-8206.2003.00198.x.

424 Nakamura, Y., Matsumoto, H., \& Todoki, K. (2002). Endothelium-dependent vasorelaxation

425 induced by black currant concentrate in rat thoracic aorta. The Japanese Journal of

426 Pharmacology, 89, 29-35. doi: 10.1254/jjp.89.29.

427 Newell, J., Higgins, D., Madden, N., Cruickshank, J., Einbeck, J., McMillan, K., \& McDonald,

428 R. (2007). Software for calculating blood lactate endurance markers. Journal of Sports Sciences, 429 25, 1403-1409. doi: 10.1080/02640410601128922.

430 Sugawara, J., Tanabe, T., Miyachi, M., Yamamoto, K., Takahashi, K., Iemitsu, M., Otsuki, T., 431 Homma, S., Maeda, S., Ajisaka, R., \& Matsuda, M. (2003). Non-invasive assessment of cardiac 432 output during exercise in healthy young humans: comparison between Modelflow method and

As accepted for publication, http://journals.humankinetics.com/ijsnem 
As accepted for publication, http://journals.humankinetics.com/ijsnem

433 Doppler echocardiography method. Acta Physiologica Scandinavica, 179, 361-366. doi:

$434 \quad$ 10.1046/j.0001-6772.2003.01211.x

435 Vukovich, M.D., \& Dreifort, G.D. (2001). Effect of beta-hydroxy beta-methylbutyrate on the

436 onset of blood lactate accumulation and $\mathrm{V}(\mathrm{O})(2)$ peak in endurance-trained cyclists. The Journal

437 of Strength and Conditioning Research, 15, 491-497.

438 Wedick, N.M., Pan, A., Cassidy, A., Rimm, E.B., Sampson, L., Rosner, B., Willett, W., Hu, 439 F.B., Sun, Q., \& van Dam, R.M. (2012). Dietary flavonoid intakes and risk of type 2 diabetes in

440 US men and women. American Journal of Clinical Nutrition, 95, 925-933. doi:

$441 \quad$ 10.3945/ajcn.111.028894.

442 Xu, J.W., Ikeda, K., \& Yamori Y. (2004). Cyanidin-3-glucoside regulates phosphorylation of 443 endothelial nitric oxide synthase. FEBS Letters, 574, 176-180. doi:

444 http://dx.doi.org/10.1016/j.febslet.2004.08.027

445 Zembron-Lacny, A., Gajewski, M., Naczk, M., \& Siatkowski, I. (2013). Effect of shiitake

446 (Lentinus edodes) extract on antioxidant and inflammatory response to prolonged eccentric

447 exercise. Journal of Physiology and Pharmacology, 64, 249-254.

448 Zhu, Y., Ling, W., Guo, H., Song, F., Ye, Q., Zou, T., Li, D., Zhang, Y., Li, G., Xiao, Y., Liu,

449 F., Li, Z., Shi, Z., \& Yang, Y. (2013). Anti-inflammatory effect of purified dietary anthocyanin

450 in adults with hypercholesterolemia: a randomized controlled trial. Nutrition, Metabolism and

451 Cardiovascular Diseases, 23, 843-849. doi: 10.1016/j.numecd.2012.06.005.

452 Zhu, Y., Xia, M., Yang, Y., Liu, F., Li, Z., Hao, Y., Mi, M., Jin, T., \& Ling, W. (2011). Purified

453 anthocyanin supplementation improves endothelial function via NO-cGMP activation in

454 hypercholesterolemic individuals. Clinical Chemistry, 57, 1524-1533. doi:

455 10.1373/clinchem.2011.167361.

As accepted for publication, http://journals.humankinetics.com/ijsnem 
As accepted for publication, http://journals.humankinetics.com/ijsnem

456 Ziberna, L., Lunder, M., Tramer, F., Drevenšek, G., \& Passamonti, S. (2013). The endothelial

457 plasma membrane transporter bilitranslocase mediates rat aortic vasodilation induced by

458 anthocyanins. Nutrition, Metabolism and Cardiovascular Diseases, 23, 68-74. doi:

$459 \quad$ 10.1016/j.numecd.2011.02.005.

460

$461 \quad$ Figure legends

462

463

464

465

466

467

468

469

470

471

472

473

474

475

476

477

478

As accepted for publication, http://journals.humankinetics.com/ijsnem 
As accepted for publication, http://journals.humankinetics.com/ijsnem

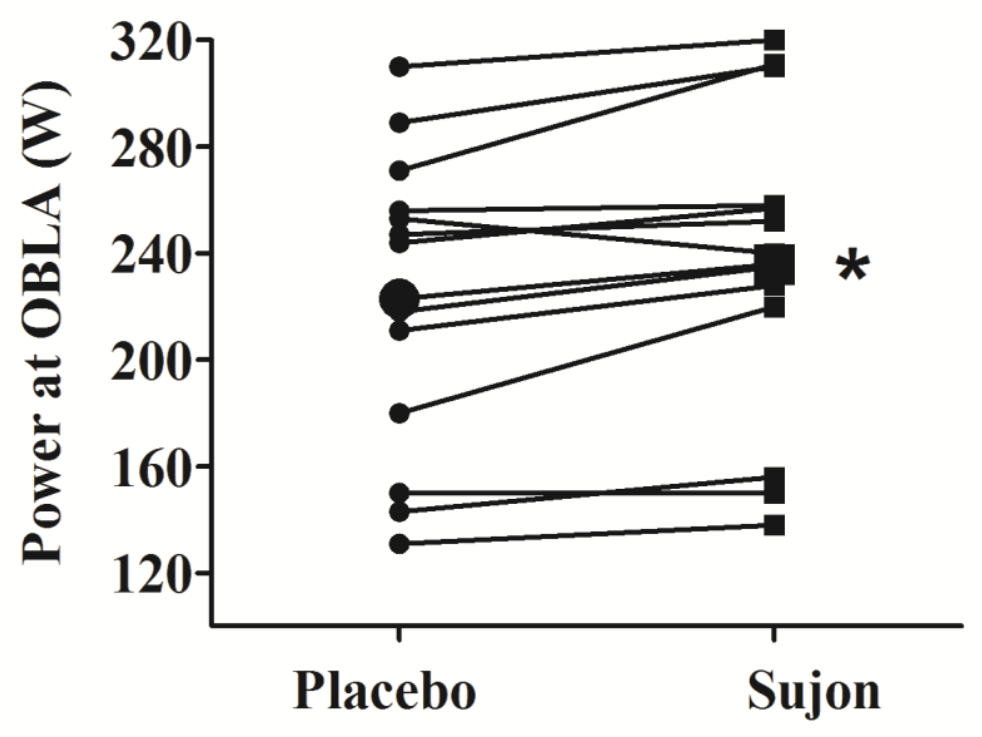

481

482 Fig.1. Power values of participants at a lactate value of $4 \mathrm{mmol} \cdot \mathrm{L}^{-1}(\mathrm{OBLA})$ for placebo and after 4837 days of Sujon New Zealand blackcurrant powder intake. Large symbols indicate mean values.

$484 *$, difference between placebo and Sujon New Zealand blackcurrant powder. 


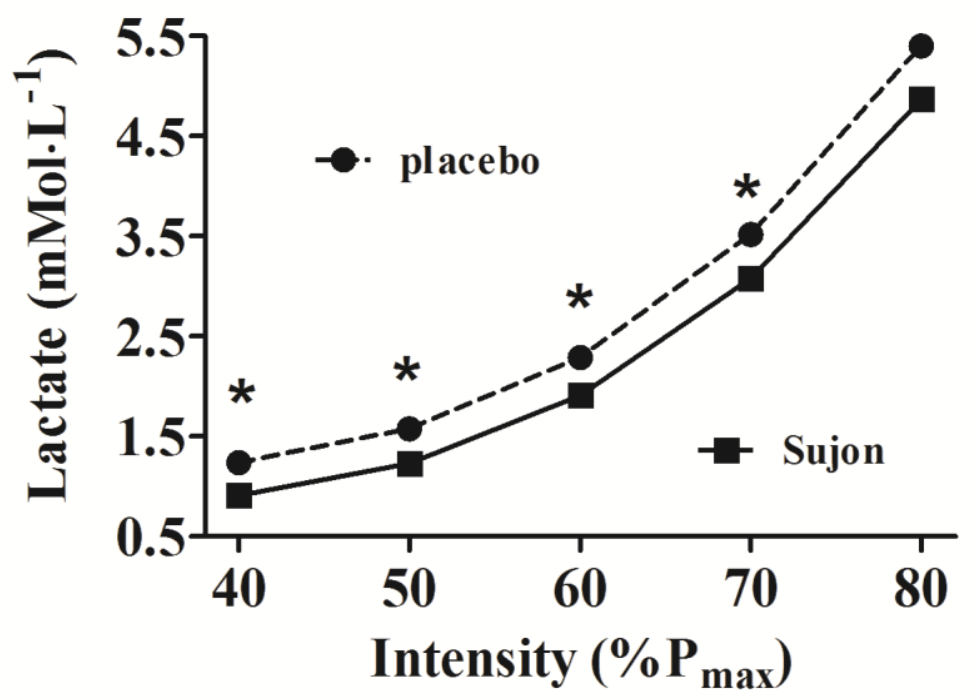

496

497 Fig. 2. Relationship between cycling intensity and lactate. Intensity was expressed as a

498 percentage of maximum power $\left(\% \mathrm{P}_{\max }\right) . *$, difference between placebo and Sujon New Zealand

499 blackcurrant powder. Values are mean \pm SD.

500

501

502

503

504

505

506

507

508

As accepted for publication, http://journals.humankinetics.com/ijsnem 


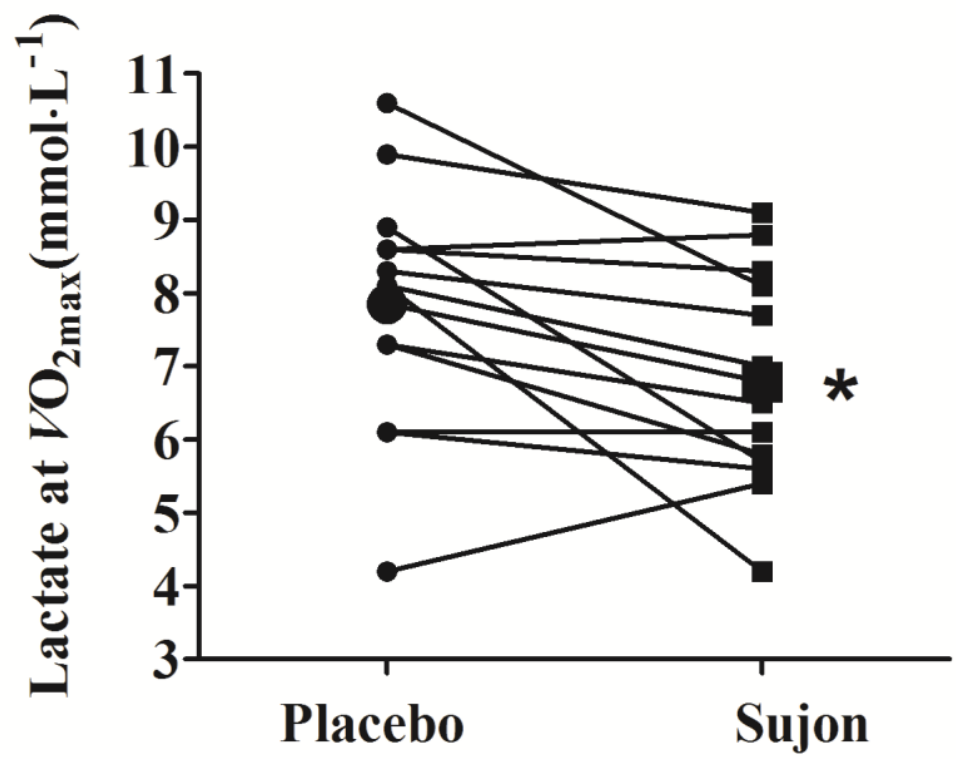

516 Fig. 3. Lactate values of participants 3 min after completion of the maximum oxygen uptake

517 protocol. Large symbols indicate mean values. Mean lactate values were lower after 7 days

518 intake of Sujon New Zealand blackcurrant powder. *, difference between placebo and Sujon

519 New Zealand blackcurrant powder. 
As accepted for publication, http://journals.humankinetics.com/ijsnem 

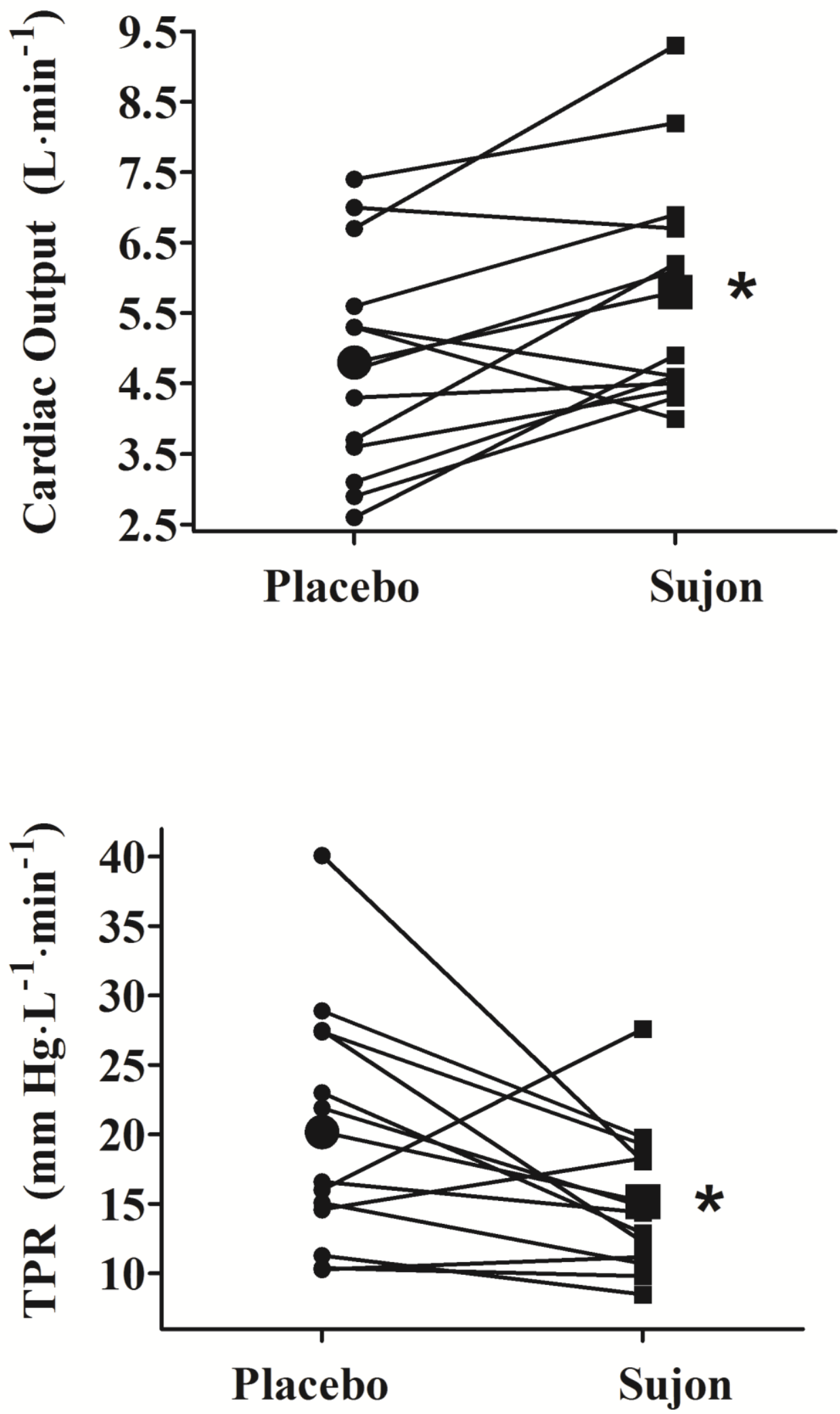
As accepted for publication, http://journals.humankinetics.com/ijsnem

526 Fig. 4. Resting cardiac output (A) and resting total peripheral resistance (TPR) (B) of

527 participants. Large symbols indicate mean values. Mean values for cardiac output and TPR were

528 higher and lower, respectively, after 7 days intake of Sujon New Zealand blackcurrant powder. *,

529 difference between placebo and Sujon New Zealand blackcurrant powder.

530

531

532

As accepted for publication, http://journals.humankinetics.com/ijsnem 
As accepted for publication, http://journals.humankinetics.com/ijsnem

Table 1. Cardiovascular responses at during cycling at $40 \%, 50 \%, 60 \%, 70 \%$ and $80 \% \dot{\mathrm{V}} \mathrm{O}_{2 \max }$.

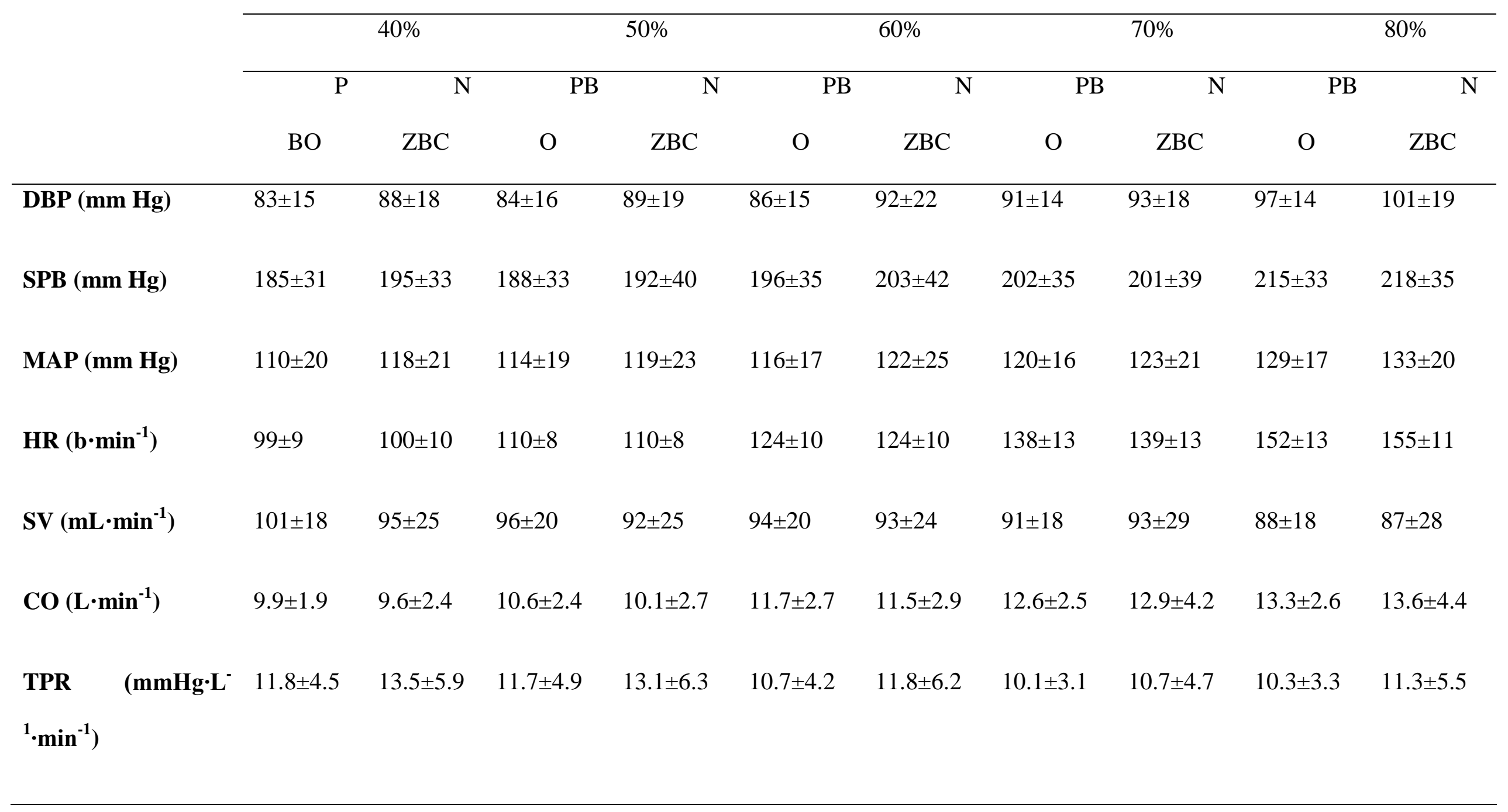


As accepted for publication, http://journals.humankinetics.com/ijsnem

PBO, placebo; NZ BC, Sujon New Zealand blackcurrant; DPB, diastolic blood pressure; SBP, systolic blood pressure; MAP, mean arterial

535 pressure; HR, heart rate; SV, stroke volume; CO, cardiac output; TPR, total peripheral resistance. Data of ten subjects. There were no differences

between placebo and Sujon New Zealand blackcurrant for a cardiovascular response at each intensity.Values are mean \pm SD.

As accepted for publication, http://journals.humankinetics.com/ijsnem 
As accepted for publication, http://journals.humankinetics.com/ijsnem 